\title{
Stromal Sarcoma
}

National Cancer Institute

\section{Source}

National Cancer Institute. Stromal Sarcoma. NCI Thesaurus. Code C6926.

A malignant neoplasm characterized by the presence of atypical mesenchymal-stromal cells. Representative examples include endometrial stromal sarcoma and prostate stromal sarcoma. 